\title{
Assessment of water resources of the Asa river basin in Southern of Kazakhstan under conditions of climate change
}

\author{
Madina Nabiollina ${ }^{1 *}$, Yermekkul Zhaparkulova ${ }^{1}$, and Anvar Sherov ${ }^{2}$ \\ ${ }^{1}$ Kazakh National Agrarian University, Department of Water Resources and Land Reclamation, \\ 050051, Almaty, Kazakhstan \\ ${ }^{2}$ Tashkent Institute of Irrigation and Agricultural Mechanization Engineers, Department of irrigation \\ and drainage systems operation, 100000, Tashkent, Uzbekistan
}

\begin{abstract}
In the Address to the people of Kazakhstan dated January 30, 2017, the President of the Republic of Kazakhstan emphasized the need for technological modernization of economic sectors. In connection with this task, the Government of the Republic adopted the State Program for the Development of the Agro-Industrial Complex of the Republic of Kazakhstan for 2017-2021, aimed at solving urgent problems of the water sector of the economy [1]. The reason for climate change is the dynamic processes on Earth, external influences, such as fluctuations in the intensity of solar radiation, and, more recently, human activities. The article presents a study assessing the water resources of the Asa River. Water intake and water supply, formation and occurrence of groundwater level, condition of collector-drainage water, mineralization. The article given methods and solutions for the disposal of water resources.
\end{abstract}

\section{Introduction}

The reason for climate change is the dynamic processes on Earth, external influences, such as fluctuations in the intensity of solar radiation, and, more recently, human activities [2]. Climate change is the most pressing issue facing our generation. The overall focus of human development is ultimately oriented towards increasing the potential of a person's abilities and expanding his freedom. Climate change threatens the very essence of human freedoms and severely limits choice. The prospects for the further development of humanity will directly depend on how the modern world copes with climatic changes.

Failure to solve this problem will doom $40 \%$ of the world's poorest people - about 2.6 billion people - to the future with progressively decreasing opportunities [3].

The threshold of dangerous climate change is considering an increase in temperature by about $2^{\circ} \mathrm{C}[3]$.

The volumes of water intake, water supply to irrigated lands and mineralization of irrigation water. The results of summarizing the long-term materials of the

Zonal Hydro-Geological and Reclamation Center, the South Kazakhstan Hydrogeological and Reclamation Expedition show that at present the actual volumes of water intake and water supply do not provide the needs of agricultural crops with the required volumes of

\footnotetext{
* Corresponding author: nabiollina_73@mail.ru
} 
water. The average indicators of water supply volumes (table 1) per 1 ha for irrigated lands of Zhambyl oblast ranged from 3561 to $5988 \mathrm{~m}^{3} / \mathrm{ha}$.

Table 1. Water intake and water supply in River Basin Asa-Talas

\begin{tabular}{|c|c|c|c|c|c|c|}
\hline \multirow{3}{*}{$\begin{array}{c}\text { Name } \\
\text { areas }\end{array}$} & \multirow[b]{3}{*}{ Year } & \multirow{3}{*}{$\begin{array}{l}\text { The } \\
\text { presence } \\
\text { of } \\
\text { irrigated } \\
\text { land, } \\
\text { thousand } \\
\text { hectares }\end{array}$} & \multirow{3}{*}{$\begin{array}{l}\text { Actually } \\
\text { watered, taking } \\
\text { into account the } \\
\text { moisture } \\
\text { charge, } \\
\text { thousand } \\
\text { hectares }\end{array}$} & \multicolumn{3}{|c|}{ Water consumption for irrigation } \\
\hline & & & & \multirow{2}{*}{$\begin{array}{l}\text { Water } \\
\text { intake, } \\
\text { mln. } \mathrm{m}^{3}\end{array}$} & \multicolumn{2}{|c|}{ water supply } \\
\hline & & & & & $\mathrm{mln} \cdot \mathrm{m}^{3}$ & $\begin{array}{c}\text { irrigation } \\
\text { norm (gross), } \\
\mathrm{m}^{3} / \mathrm{ha}\end{array}$ \\
\hline \multirow{8}{*}{$\begin{array}{c}\text { Zhambul } \\
\text { oblast } \\
\text { (River } \\
\text { Basin } \\
\text { Asa- } \\
\text { Talas) }\end{array}$} & 2007 & 105,6 & 84,421 & 500,1 & 377,4 & 3574 \\
\hline & 2008 & 105,6 & 86,358 & 565,5 & 468,3 & 4435 \\
\hline & 2009 & 105,9 & 89,839 & 541,9 & 414,2 & 3913 \\
\hline & 2010 & 105,9 & 90294 & 660,1 & 540,7 & 5988 \\
\hline & 2011 & 105,9 & 93,854 & 656,1 & 467,1 & 4977 \\
\hline & 2012 & 105,9 & 95,963 & 501,7 & 341,7 & 3561 \\
\hline & 2013 & 106,0 & 93,046 & 565,5 & 390,8 & 4199 \\
\hline & medium & 106,0 & 90,539 & 505,8 & 428,6 & 4378 \\
\hline \multicolumn{3}{|c|}{ The coefficient of variation, $\%$} & & 11,53 & 15,77 & \\
\hline
\end{tabular}

\section{Materials and Methods}

The productivity of irrigated lands depends not only on the water availability of irrigated lands, but also on the quality of irrigation water. The results of the studies showed that the mineralization of the Asa and Talas rivers increases with the flow. For example, in the AsaTalas river basin, mineralization of irrigation water downstream in the river. Ters (Zhualinsky district) is $0.395 \mathrm{~g} / 1$, and in the Asa district Aisha-Bibi district (Zhambyl district) - $0.397 \mathrm{~g} / \mathrm{l}$, in the Birlesu-Enbek district (Zhambyl district) - $0.527 \mathrm{~g} / \mathrm{l}$. (table 2).

Table 2. Ionic composition of irrigation water

\begin{tabular}{|c|c|c|c|c|c|c|c|c|}
\hline \multirow{2}{*}{$\begin{array}{c}\text { Name of } \\
\text { basins }\end{array}$} & \multicolumn{4}{|c|}{ Anions } & \multicolumn{3}{c|}{ Cations } & $\begin{array}{c}\Sigma_{\text {сол., }} \\
\mathrm{g} / 1\end{array}$ \\
\cline { 2 - 8 } & $\mathrm{CO}_{3}{ }^{2-}$ & $\mathrm{HCO}_{3}{ }^{-}$ & $\mathrm{Cl}^{-}$ & $\mathrm{SO}_{4}^{2-}$ & $\mathrm{Ca}^{2+}$ & $\mathrm{Mg}^{2+}$ & $\mathrm{Na}^{+}$ & \\
\hline $\begin{array}{c}\text { Asa } \\
\begin{array}{c}\text { Birlesy } \\
\text { Enbek) }\end{array}\end{array}$ & $\frac{0,234}{3,84}$ & $\frac{0,037}{1,04}$ & $\frac{0,094}{1,96}$ & $\frac{0,064}{3,20}$ & $\frac{0,019}{1,60}$ & $\frac{0,047}{2,04}$ & 0,495 \\
\hline
\end{tabular}

Analysis of the ion-salt composition of irrigation water shows that a deteriorating factor in the quality of irrigation water is the presence in their composition of alkaline salts $\mathrm{Na}_{2} \mathrm{CO}_{3}$ (normal soda) and $\mathrm{NaHCO}_{3}$ (sodium bicarbonate). These salts were found in the Asa and Talas rivers. Indicators of water quality according to SAR (sodium adsorption ratio), RSC (residual sodium carbonate) varies within acceptable limits (table 3) [4].

Table 3. Quality indicators of irrigation water in various irrigation systems

\begin{tabular}{|c|c|}
\hline & Indicators \\
\hline
\end{tabular}




\begin{tabular}{|c|c|c|c|c|c|c|c|c|}
\hline \multirow{2}{*}{$\begin{array}{l}\text { A place } \\
\text { selection }\end{array}$} & \multirow{2}{*}{$\begin{array}{l}\text { Mineral } \\
\text { ization } \\
\text { (С), Г/л }\end{array}$} & \multirow[b]{2}{*}{$\mathrm{pH}$} & \multirow{2}{*}{$\begin{array}{c}\text { by } \\
\text { "residual } \\
\text { sodium } \\
\text { carbonate } \\
\text { " (RSC), } \\
\mathrm{mEq} / 1\end{array}$} & \multirow{2}{*}{$\begin{array}{c}\text { in } \\
\text { content } \\
\mathrm{Mg}^{2+}, \%\end{array}$} & \multirow{2}{*}{$\begin{array}{c}\text { by I.N. } \\
\text { Antipova- } \\
\text { Karataeva } \\
\text { and } \\
\text { G.M. } \\
\text { Kadera }\end{array}$} & \multirow{2}{*}{$\begin{array}{l}\text { Ratio } \\
\frac{\mathrm{Cl}^{-}}{\mathrm{SO}_{4}^{2-}}\end{array}$} & \multicolumn{2}{|c|}{$\begin{array}{l}\text { by sodium } \\
\text { adsorption } \\
\text { ratio }\end{array}$} \\
\hline & & & & & & & $\begin{array}{c}\text { SA } \\
\text { R }\end{array}$ & $\begin{array}{l}\mathrm{SA} \\
\mathrm{R}^{*} \\
\text { (US } \\
\mathrm{A})\end{array}$ \\
\hline $\begin{array}{c}\text { Talas } \\
\text { v. } \\
\text { Tuimeken } \\
\text { t. }\end{array}$ & 0,48 & 8,75 & $-0,68$ & 43,5 & 1,89 & 0,35 & 1,53 & 7,19 \\
\hline $\begin{array}{c}\text { v.Besagas } \\
\text { h, Asa- } \\
\text { Talas }\end{array}$ & 0,576 & 8,7 & -1 & 40,0 & 1,60 & 0,26 & 1,90 & 7,14 \\
\hline r. Talas & 0,396 & 8,75 & $-0,88$ & 37,5 & 3,96 & 0,80 & 0,72 & 7,23 \\
\hline
\end{tabular}

The deficit of irrigation water and the deterioration of the ecological and meliorative state of irrigated lands have predetermined a decrease in productivity and other agricultural crops. Low crop yields also occur on irrigated lands in Zhambyl oblast.

\section{Results and Discussion}

Thus, the research results show that irrigation systems in all the southern regions of Kazakhstan not provided with the necessary volumes of irrigation water. This leads to a violation of the regime and technology of irrigation of agricultural crops and, consequently, to a decrease in crop yields. In addition, a large volume of irrigation water loss due to infiltration intensified the degradation processes in the root-inhabited soil layer and worsened the ecological and reclamation state of irrigated lands. Therefore, in the current situation on the irrigated lands of Kazakhstan, in order to develop resource-saving integrated water-land resources management technologies, it is necessary to establish the basic patterns of the formation of a ground regime on irrigation systems.

Analysis of the dynamics of the level of occurrence of groundwater and water intake shows that their greatest rise strictly correlated with each other. Therefore, the greater the intake and volumes of infiltration losses, the closer the groundwater level to the surface $[5]$.

According to the formation of groundwater, the Asa-Talas river basin can be divided into two parts: mountain and foothill-plain $[6,9]$. In the mountainous part, composed of highly dislocated rocks with natural drainage, developed deep underground waters circulating through cracks and a permeable horizon, only in small areas. In the valleys and inter-valley depressions, groundwater gives rise to springs.

The surface waters of the Asa and Talas rivers take an active part in groundwater nutrition. At the same time, the influx of groundwater from the mountainside also plays a dominant role in the input part. In the period before irrigation, the hydrological factor was predominant in the formation of the groundwater regime, with the subordinate value of the climatic factor $[6,9]$. The effect of irrigation of agricultural crops on the dynamics of the ground level also takes place on the irrigated lands of the Asa-Talas river basin. The results of long-term observations of the dynamics of the water supply system showed that the infiltration losses of irrigation water during the irrigation period led to a widespread increase in their level, and during the non-growing season, to a decrease [7].

An analysis of the patterns of groundwater formation on irrigated lands shows that the maximum rise in the occurrence level occurs during the growing season. After the end of 
the irrigation season, an intensive decrease in their occurrence level occurs. This confirms the dynamics of the level of groundwater occurrence in the irrigation systems of the AsaTalas river basin. It established that in the Bayzak district of the Zhambyl region, the maximum amplitude of fluctuations in the level of occurrence of soil was $2.40 \mathrm{~m}$ (well 3). On the irrigated lands of Zhambyl region, the amplitude of the oscillation of the bedding level was $2.30 \mathrm{~m}$ (well 26) [8].

In conditions of growing deficit of irrigation water and with close occurrence of groundwater, one of the ways to solve this problem is to use groundwater for subirrigation. However, the use of groundwater without taking into account their mineralization and ionsalt composition can lead to an increase in the degradation process in the root layer of the soil. This process confirmed by the experience of operating irrigation systems, where the close occurrence of mineralized groundwater led to intense salinization, alkalineization and alkalization of the root habitat of the soil [9].

High alkalinity characterized by groundwater in the Asa-Talas river basin. The results of the synthesis of materials on groundwater salinity show that their indicators are less than $3 \mathrm{~g} / \mathrm{l}$ and vary within $0.279-2.624 \mathrm{~g} / \mathrm{l}$. Changes in the salinity of groundwater over a wide range predetermined their high variability. Therefore, the variability of the amount of salts is $104.3 \%$.

An analysis of the ionic composition of groundwater shows that among the anions there is no $\mathrm{CO}_{3}{ }^{2-}$. However, the high alkalinity of groundwater in the Asa-Talas river basin confirmed by the content of HCO3-. Mineralization according to data from the 14th well in the Bayzak region varies within 0.024-0.451 g/l. At the same time, the share of HCO3for salts reaches $63.2 \%$ of the total mineralization [10].

The analysis of the data shows that with increasing soil mineralization, the content of sulfates - $\mathrm{SO}_{4}{ }^{2-}$ increases. For example, when salinity of groundwater is $0.714 \mathrm{~g} / \mathrm{l}$, the concentration of $\mathrm{SO}_{4}{ }^{2-}$ is $0.048 \mathrm{~g} / \mathrm{l}$, and their share for salts is $6.7 \%$. With soil mineralization of $2.624 \mathrm{~g} / 1$, the concentration of $\mathrm{SO}_{4}{ }^{2-}$ reaches $1.738 \mathrm{~g} / 1$ and amounts to $66.2 \%$ of the total salt. A similar pattern observed on irrigated lands in other areas of the Asa-Talas river basin.

Ecological and land reclamation assessment of groundwater. The use of groundwater for irrigation and sub irrigation requires the establishment of their limits at which the ecological and reclamation stability of irrigated lands maintained. Therefore, to establish the ecological safe limits for the use of groundwater for irrigation and sub irrigation, using existing methods, an assessment was made of the possibility of salinization, salinization, and alkalization of soils.

Groundwater in the Asa-Talas river basin in terms of total salinity (C) in Zhambyl district is classified as fresh, of good quality; in Bayzak - fresh and medium brackish, of good and poor quality.

\section{Conclusion}

According to the indicator of hydrogen ions $(\mathrm{pH})$, groundwater is classified as neutral and slightly alkaline [10]. Studies have shown that on the irrigated lands of the Zhambyl region, the salinity of groundwater is less than $1 \mathrm{~g} / \mathrm{l}$. Therefore, groundwater in this area for $90 \%$ of the irrigated land can used for sub irrigation. SAR values vary between 0.46 6.17 , which is less than the permissible limit of 10 , but in some places, it reaches 18 . The main limiting factor for the use of groundwater in all areas is the high content of magnesium cation, which in many places exceeds $50 \%$, which is more than the allowable limit.

Collector-drainage water and their quality. Experimental studies of Kazakh Scientific Research Institute of Water Economy established that on irrigation systems where the 
irrigation regime was used, and the groundwater level, as a rule, did not rise above $2.0 \mathrm{~m}$, $20.25 \%$ of the amount of water absorbed into the soil was spent on filtration. In the inter irrigation period, $30-40 \%$ of these losses returned due to the capillary rise of groundwater into root-inhabited horizons. Taking into account technological losses in the temporary irrigation network (5\%), infiltration (15-20\%) and discharge from irrigated fields (10$15 \%$ ), irrigation norms - grossly increased by $30-35 \%$ relative to norms, established by the bioclimatic method. Therefore, the estimated water supply on irrigated lands, even taking into account the high efficiency of the irrigation network (0.65-0.70), was achieved by increasing the design water intake by $20-25 \%$, that is, with a head water intake exceeding 10 thousand $\mathrm{m} 3$ / ha. With such volumes of water intake into irrigation systems located in poorly drained territories, the sizes of drainage flow usually increased to $25-40 \%$ of the water intake. These waters, as a rule, returned to the riverbed, and worsened the hydro chemical composition of the river flow.

Currently, the most effective measure for the disposal of collector-drainage water is their use for irrigation of agricultural crops. Using them for irrigation and leaching can increase the water availability of irrigated lands and reduce the rate of pollution of water and land resources. Utilization of collector-drainage water by using it for irrigation and flushing will increase the intensity of small biological and reduce the intensity of large geological circuits.

Based on a synthesis of experimental materials, it was established that when irrigating crops with collector-drainage water. The assessment of the soil-ecological condition of irrigated lands and, accordingly, the establishment of parameters for the technology for controlling the water-salt regime of soils should base on the identification of the rate and direction of the flow of soil-ecological processes in the root habitat thicker than soils. One of the main requirements when using collector-drainage water for irrigation and leaching is that their mineralization should always be less than the concentration of soil solution. Therefore, when using saline water for irrigation and leaching of saline soils, it is necessary to control the salinity of the soil solution ( $\mathrm{Spr}$ ) and compare it with the salinity of the return water (Sor) used for irrigation and leaching. At $\mathrm{Spr}<\mathrm{Sop}$, soil salinization processes occur in the root habitat. Therefore, one of the main requirements when using groundwater and drainage water for irrigation and leaching is to comply with the condition $\mathrm{Sp}>\mathrm{Sor}$, in which salts are washed out with infiltration water, and their reserves in the root habitat are reduced.

The proposed measures for water management (surface, ground) will:

- reduce the technological losses of irrigation water (for evaporation, filtration, and discharge)

- increase the volume of groundwater use for sub irrigation

- reduce drainage and waste flow, slow down the rate of soil degradation by reduction of filtration losses of irrigation water

- Inter-row cultivations and passage of tillage equipment on dry furrows (when irrigation through a furrow). These measures will provide economically acceptable crop yields with water shortages, increase the sustainability of the development of irrigated agriculture, reduce the rate of pollution of water resources, and improve the environmental situation in the areas where the rural population lives.

Generalizations of the research results show that the use of collector-drainage water for irrigation of crops requires establishing the pace and direction of the flow of soil-ecological processes in the root-inhabited soil layer. The results of such studies allow us to establish the optimal parameters of the technology for using collector-drainage water for irrigation of agricultural crops. Due to climate change, water scarcity is increasing, and therefore it will be necessary to switch to resource-saving technologies for using water resources starting today. 


\section{References}

1. A.Zh. Akbasova, E.U. Zhamalbekov et al., Ecological encyclopedia (Almaty, 303, 2007)

2. Annual report of the Shu-Talas Basin Inspectorate for the regulation of use and protection of water resources, Taraz, $\mathbf{2 8 3}$ (2006)

3. Cadastre of reclamation of arable lands of Zhambyl region, Taraz, 24 (2007)

4. D.D. Dzhumadilov, K.Sh. Kozhanov., R.K. Bekbaev, Ecological and reclamation assessment of water and land resources in cultivated ecosystems in the basin of TalasAsa, Materials of the international scientific-practical conference "Industrial-innovative development" - the basis of economics (Shymkent, 357-360, 2006)

5. R.K. Bekbaev, Soil-ecological processes and methods of their regulation in cultivated ecosystems of Kazakhstan (Taraz, 262, 2006)

6. S.R. Ibatullin, R.K. Bekbayev, F.F Vyshpolsky, U.K. Bekbaev, Taraz, 55 (2008)

7. U.K. Bekbaev, E.D. Zhaparkulova, RA Jaysambekova, Taraz, 37 (2008)

8. U.K. Bekbaev, Taraz, 24 (2009)

9. F.F. Vyshpolsky, R.K. Bekbayev, E.D. Zhaparkulova, Final Report on "Development of resource-saving technologies of cultivation with the use of organic land reclamation in the adaptive-landscape system of agriculture" (2006-2008), 0208РК01625; 0106РK01324, Taraz, (2008)

10. E.D. Zhaparkulova, R.A. Zhaisambekova, Taraz, 18-23 (2010)

11. Y. Zhaparkulova, M. Nabiollina M, B. Amanbayeva, E3S Web of Conferences, 97, (2019) 